\title{
Fabrication of active cooling e-Textiles
}

\author{
Seung-A Lee, Changhwan Lee, Kitai Kim and Jooyong Kim ${ }^{\dagger}$
}

Department of Organic Materials and Fiber Engineering, Soongsil University, Seoul, 156-743, Korea

\section{스마트 의류용 전도성 직물의 제조 및 특성 분석}

\author{
이승아 · 이창환 $\cdot$ 김기태 · 김주용 ${ }^{\dagger}$ \\ 숭실대학교 유기신소재·파이버공학과
}

(Received: September 23, 2008/Revised: October 20, 2008/Accepted: November 3, 2008)

\begin{abstract}
Cooling function is definitely one of the most desirable attribute of clothing. In spite of the recent progress on phase changing material(PCM) research, the final products with sufficient amount of cooling capability have not yet to be developed in market. A new concept of cooling fabrics has been proposed by applying "Peltier effect" to textile materials. It occurs whenever electrical current flows through two dissimilar conductors; depending on the direction of current flow, the junction of the two conductors is absorbed or released heat. This effect has been tested on P-type and N-type conducting polymers. A P-type conductive polypyrrole coated fabric was synthesized by in-situ polymerization on plain weave PET to make conductive fabrics. And an N-type electrically conductive material was synthesized by treatment of MWNT and polyethyleneimine(PEI). A noticeable amount of temperature difference has been found on the fabrics.
\end{abstract}

Keywords: cooling fabrics, Peltier effect, P-type, N-type, conducting polymers, polypyrrole, MWNT, polyethyleneimine

\section{Introduction}

Recently, a cooling effect has become an important function in textile according to the change of consumer's life style and advent of functional clothes. Conventional method of cooling fabrics has a lot of defects such as weight, non-flexibility and addition of refrigerant because refrigerant circulation method has complex wiring structure ${ }^{1)}$. In this study, to complement its defects, we applied a Peltier effect that occurs whenever electrical current flows through two dissimilar conductors; depending on the direction of current flow, the junction of the two conductors is absorbed or released heat ${ }^{2)}$. Usually, P-type and N-type conducting polymers were used for a Peltier effect. However, these materials were not suitable for clothes because it is still heavy, nonflexible and difficult to manufacture the fabrics.
Hence, in this study, we should search another conductive material which has not only high conductivity but also easy control conductivity. In conducting polymer materials, a PPy(Polypyrrole) showed high conductivity, easy synthesis and excellent stabilization to oxidation.

However, the PPy also has some problems because of low mechanical property and of difficulty to synthesize by non-melting and non-fusion. To solve this problem, P-type polymer by synthesizing polymer and $\mathrm{PPy}^{3-5)}$ was used. In addition, N-type carbon nanotube polymer by synthesizing carbon nanotube and PEI has been used to prove a Peltier effect ${ }^{10,11)}$.

The purpose of this study was to investigate the prototype active cooling e-textile to flexible, wearable and portable using PPy fiber composite to be synthesized by chemical method ${ }^{6-8)}$ and MWNT-PEI which was carbon nanotube polymer composites.

${ }^{\dagger}$ Corresponding author. Tel.: +82-2-820-0621; Fax.: +82-2-817-3346; e-mail: jykim@ssu.ac.kr 


\section{Experimental}

\subsection{Materials and Samples}

To synthesize P-type PPy-PET composite fabrics, the conducting polymer polypyrrole(PPy) was synthesized. The pyrrole(Py, Mw: 67.09) as a monomer, the Anthraquinone-2-sulfonic acid (AQSA, Mw: 328.28) as a dopant and the Ferric chloride hexahydrate $\left(\mathrm{FeCl}_{3}{ }^{\prime} \mathrm{E}_{\mathrm{H}} \mathrm{H}_{2} \mathrm{O}, \mathrm{Mw}\right.$ : 270.3$)$ as a oxidant were used to coat the P-type conductive PPy in fabric. PET plain weave fabrics after conditioning were used for PPy-PET compositefabric.

To synthesize N-type MWNT-PEI composite, MWNT (Multiwall carbon nanotube, Iljin nanotech Co Ltd., purity: $95 \%$, diameter: $10-15 \mathrm{~nm}$, length: $10-20 \mu \mathrm{m}$ without refining and polyethyleneimine (PEI, molecular weight: 800) as a polymer were used. In addition, thionyl chloride $\left(\mathrm{SOCl}_{2}\right)$, anhydrous THF and chloroform were also used without refining to surface treatment of MWNT and composite synthesis.

\subsection{Synthesis of P-type PPy-PET composite fabric}

To make conducting fabrics, PPy was coated in PET fabric through in-situ polymerization after soaking PET fabrics in pyrrole monomer. In detail, according to

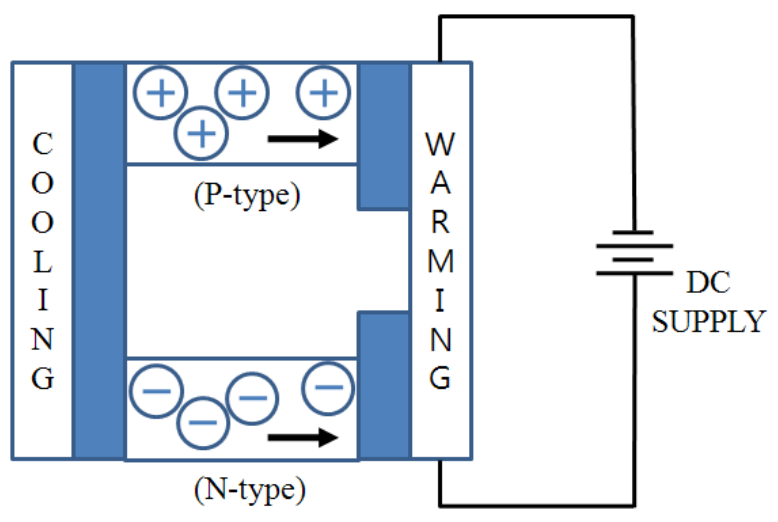

Fig. 1. General concept of Peltier effect.
ASTM D1576-84, it was inserted in the solvent composed of pyrrole $0.045 \mathrm{~mol} / 1$ as a monomer, anthraquinone-2-sulfonic acid $0.018 \mathrm{~mol} / \mathrm{l}$ as a dopant and $\mathrm{FeCl}_{3} 0.1 \mathrm{~mol} / \mathrm{l}$ as a oxidant after drying the PET fabric $(4.2 \mathrm{~g} \pm 0.05 \mathrm{~g})$ at $105^{\circ} \mathrm{C}$ in vacuum oven. The solvent was diluted by a ratio of 60 to 1 and set at $25^{\circ} \mathrm{C}$ for $6 \mathrm{hr}$ and then, synthesized p-doped polypyrrole.

After washing the compositefabric by methanol, acetone and distilled water and then drying, the PPy coated conducting PET fabric was produced.

\subsection{Synthesis of N-type MWNT-PEl composite}

\subsubsection{Surface treatment of MWNT}

After adding the $60 \%$-nitrate solvent $20 \mathrm{ml}$ in MWNT $2 \mathrm{~g}$, it treated for 30 minute in ultrasonic bath, and then it mixed at $24 \mathrm{hr}$. MWNT-COOH was filtrated using micro filtration assembly and dispersed in distilled water. This processing was repeated several times for neutralization. So, the surface treated MWNT-COOH could be obtained from neutralized MWNT after drying at $60^{\circ} \mathrm{C}$ for $24 \mathrm{hr}$. This MWNT-COOH was reacted again with $\mathrm{SOCl}_{2}$ at $65^{\circ} \mathrm{C}$ for $24 \mathrm{hr}$. This MWNT surface treated by MWNT-COCl was washed by THF and then dried at room temperature for $2 \mathrm{hr}$ after filtration as shown in Scheme 1.

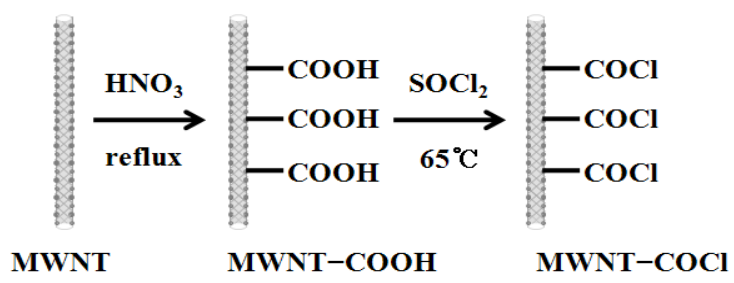

Scheme 1. Schematic diagram of MUNT modification.

\subsubsection{Synthesis of MWNT-PEI composite}

The surface treated MWNT-COCl $(81 \mathrm{mg})$ was added in $\mathrm{PEI}(7 \mathrm{ml})$ then mixed at $80^{\circ} \mathrm{C}$ for 4 days under nitrogen air flow. This material was mixed well with chloroform $(150 \mathrm{ml})$ and $\mathrm{H}_{2} \mathrm{O}(130 \mathrm{ml})$ solvent. After removing separated $\mathrm{H}_{2} \mathrm{O}$, black paste was obtained.

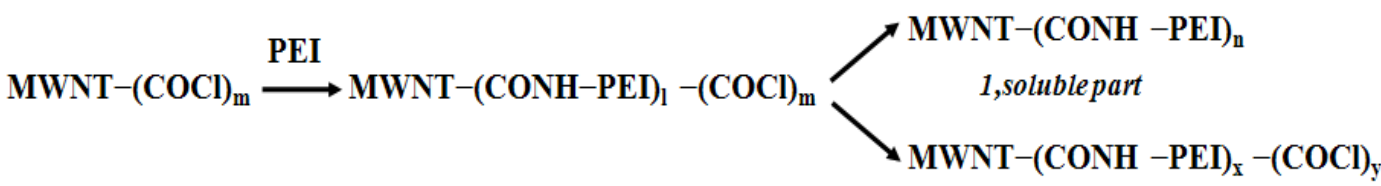

$$
\begin{aligned}
& \text { 2,insoluble part }
\end{aligned}
$$

Scheme 2. Schematic diagram of Synthesis of MWNT-PEI composite. 
This black paste was again mixed with chloroform (200ml) and then it was separated into soluble part and insoluble part. The soluble part has N-type conducting polymer function as shown in Scheme 2.

\subsection{Verification of Peltier effect}

In order to verify the application of the Peltier effect, $\mathrm{N}$-type conducting materials and P-type conducting materials were set between two cooper plates having similar conductivity.

Temperature of two plates a surface was measured using Raytek ${ }^{\circledR}$ infrared thermometer and resistance also measured by Fluke ${ }^{\circledR}$ multimeter ${ }^{9}$.

\section{Results and Discussion}

\subsection{Development of conductive fabric}

\subsubsection{P-type PPy-PET composite fabric}

A PPy was coated in PET fabric through in-situ polymerization. Fig. 3 shows the surface of fabric using scanning electron micrograph. It could be known that black PPy was coated uniformly in the surface of the fabric. Fig. 4 shows FTIR spectra of PPy coated PET fabrics before and after heat treatment at $200^{\circ} \mathrm{C}$.

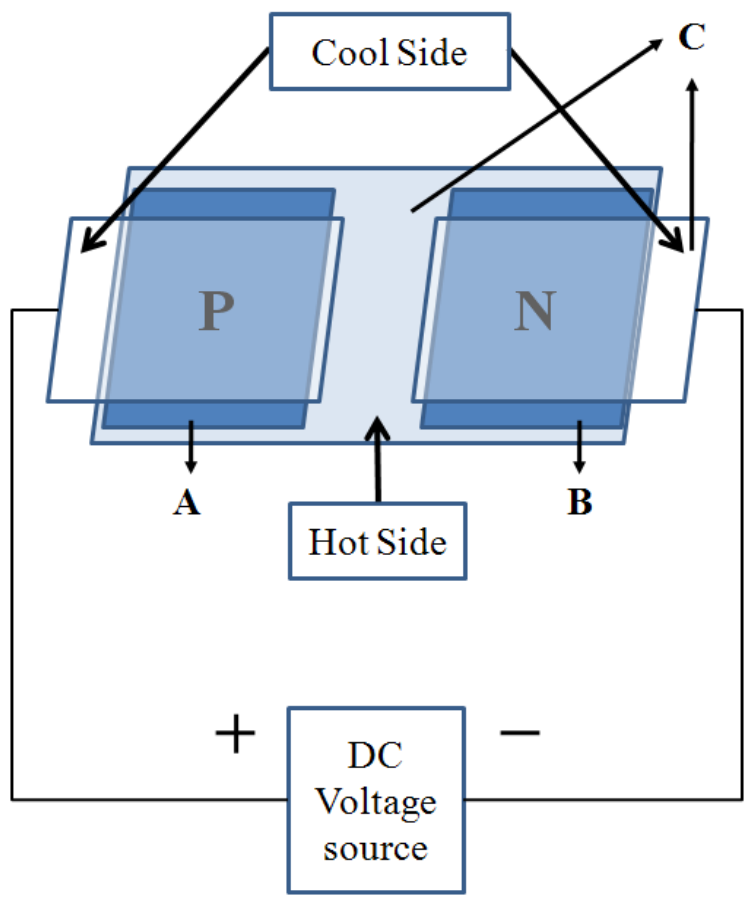

Fig. 2. An experimental set-up for cooling effect; $A$ : P-type conductive polymer fabric, B: N-type MWNT$\mathrm{PEI}$ composite material and C: copper metal plates.
Before heat treatment, $1559 \mathrm{~cm}^{-1}$ band was confirmed but, after heat treatment, this peak was disappeared. It meant that $\mathrm{C}=\mathrm{N}-/-\mathrm{C}=\mathrm{C}$ - ingredient in $1559 \mathrm{~cm}^{-1}$ band was disappeared by heat treatment. Namely, the conductive fabric has p-dopant function by adding $\mathrm{AQSA}$ (anthraquinone-2-sulfonic acid) as a dopant. The P-type conductive fabric has a lot of holes as a trace by reason that one electron has been dropped out.

\subsubsection{N-type MWNT-PEI composite material}

After acid and $\mathrm{SOCl}_{2}$ treatment, MWNT-COCl was transferred in surface of MWNT, and then reacted with PEI. Finally, it was able to obtain MWNT-PEI composite material through $\mathrm{COCl}$ ingredient of MWNT and amidation reaction. Fig. 5 shows FTIR spectra of MWNT and MWNT-COOH before and after the nitric acid surface reforming. Some peaks were found in $1728 \mathrm{~cm}^{-1}, 1254 \mathrm{~cm}^{-1}, 3400 \mathrm{~cm}^{-1}, 1602 \mathrm{~cm}^{-1}$ and $1475 \mathrm{~cm}^{-1}$. This peaks showed stretching modes of $\mathrm{C} \sim \sim \mathrm{O}, \mathrm{C}-\mathrm{O}$, $\mathrm{O}-\mathrm{H}$ and $\mathrm{C} \sim \mathrm{C}$. So, it meant that carboxylic acid was transferred in surface of MWNT by strong nitric acid.
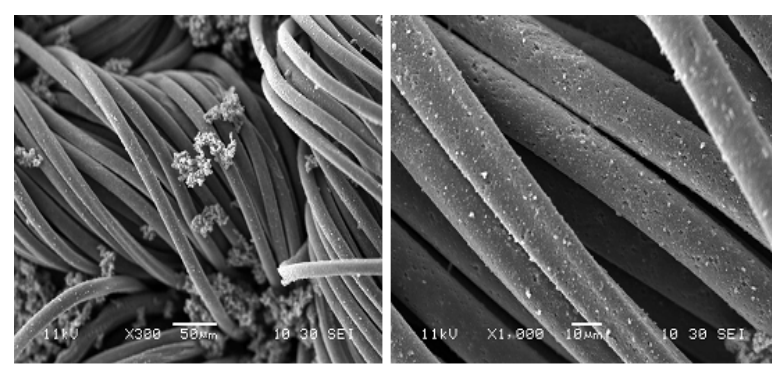

Fig. 3. Scanning electron micrograph images of PPycoated PET fabrics; (left) 300 times and (right) 1000 times.

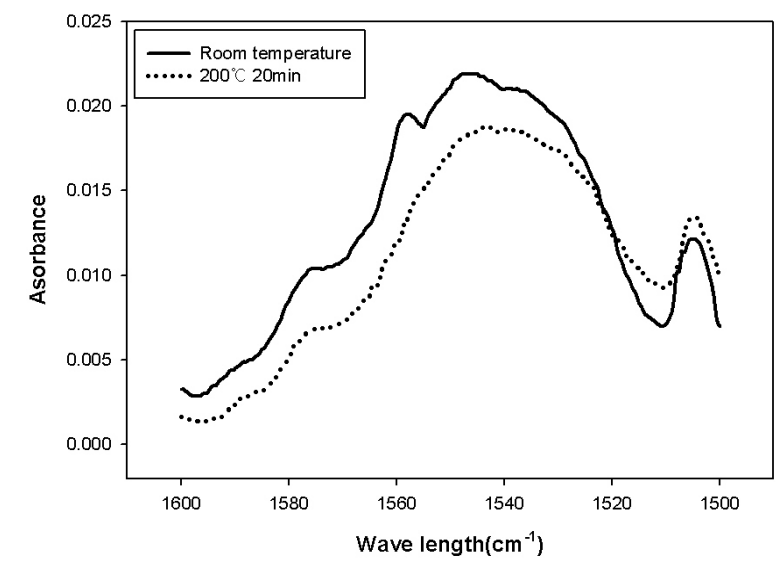

Fig. 4. FTIR spectra of polypyrrole coated PET fabrics before and after heat treatment. 
This function was reformed to MWNT-COCl by $\mathrm{SOCl}_{2}$ treatment, again. Fig. 6 shows FTIR spectra of part 1 and part 2 in Scheme 2.

The part 1 was appeared in $1668 \mathrm{~cm}^{-1}$ band that was $\mathrm{C}=\mathrm{O}$ ingredient of $\mathrm{CONH}-$. In part 2 , amid $\mathrm{C}=\mathrm{O}$ in $1641 \mathrm{~cm}^{-1}$ and $\mathrm{C}=\mathrm{O}$ peak, which was non-reacted $\mathrm{COCl}$, was observed in $1700 \mathrm{~cm}^{-1}$. Here, the soluble part 1 has n-doped function. So, N-type conductive material has higher electron density.

\subsection{Peltier effect}

In two different type of metals, the electron moves from low potential energy metal to high potential energy metal because of difference of potential energy. In addition, thermal energy was also transferred into other forms, such as emission or absorption. This is called the Peltier effect. In this study, to verify the

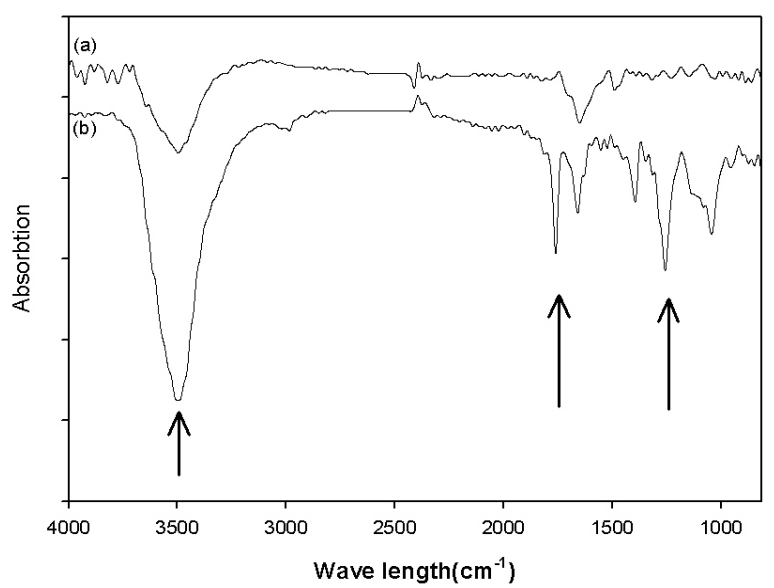

Fig. 5. FTIR spectra of (a)MWNT and (b)MWNT$\mathrm{COOH}$.

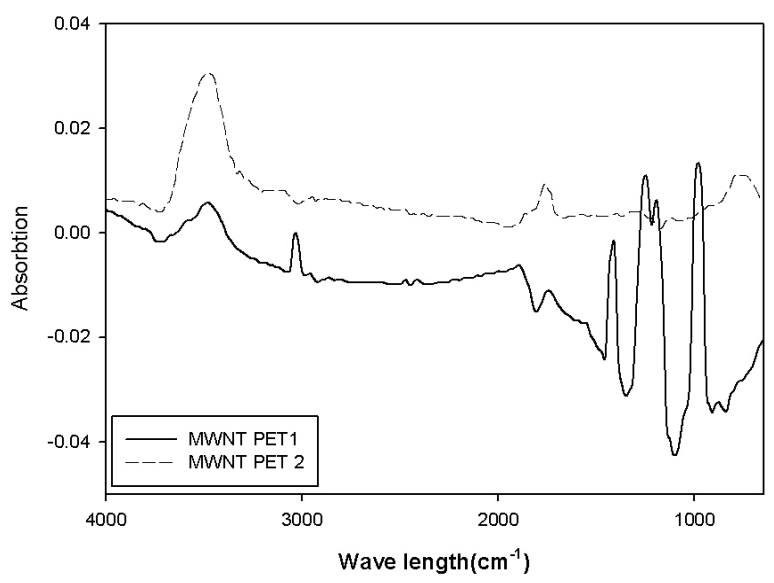

Fig. 6. FTIR spectra of MWNT PET1 and MWNT PET2.
Peltier effect, P-type PPy-PET composite fabrics and N-type MWNT-PEI composite materials were set in the two similar conductive metal plates, and then temperature of two metal plates was measured. Here, the thermal emission and absorption were observed in the upper side and the bottom side of metal because the electron transfers to the hole by an electric current in conductive fabrics.

As a result of Peltier effect experiment, there was about $5^{\circ} \mathrm{C}$ difference between upper side and bottom side. Moreover, it has a tendency to decrease, as shown in Fig. 8. It was considered that the conductive polymer was decomposed by heat in the progress of the experiment, so it was brought increasing of electric

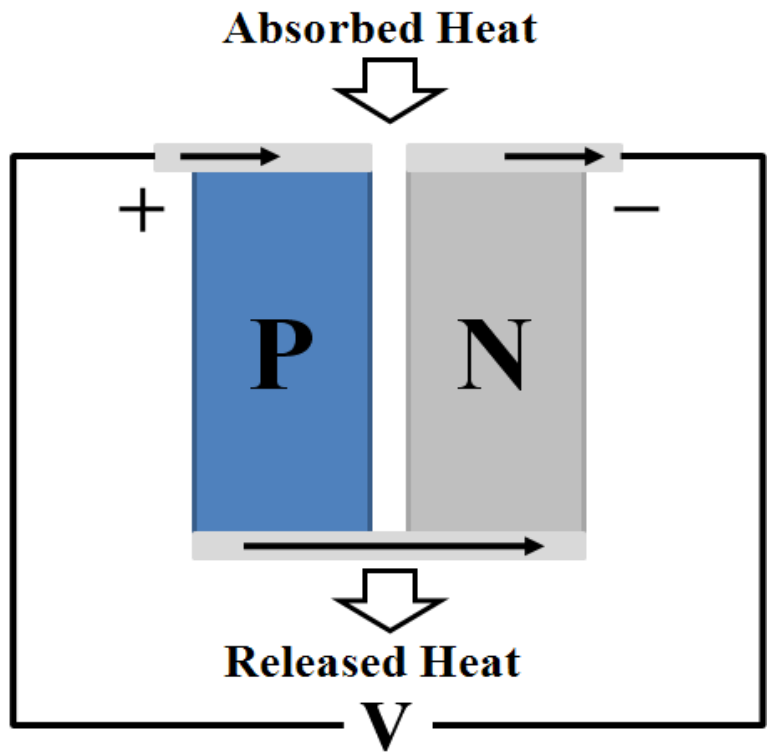

Fig. 7. Peltier principle between $\mathrm{P}$ and $\mathrm{N}$-type materials.

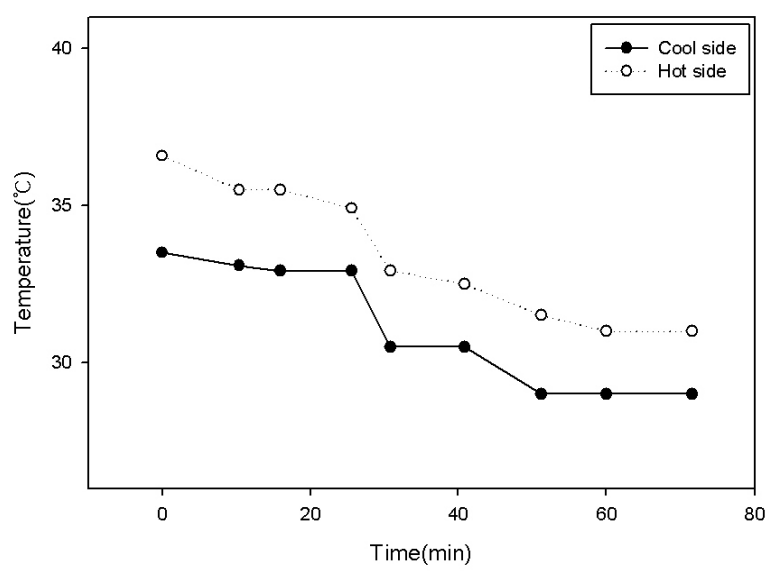

Fig. 8. Peltier effect experiments with temperature vs. time. 
resistance and decreasing of electric current. We supposed that the difference of temperature in two sides was quite low(about $5^{\circ} \mathrm{C}$ ) because the insulation value between thermal emission and thermal absorption was not operating well.

As a Peltier theory, the cooling effect between conductive polymer and metal was occurred in difference of potential energy by transferring the electron or the hole. When an electric charge transfers in polymer, heat is generated by electric resistance. Namely, this heat has offset the cooling effect between P-type conductive fabric and N-type conductive material. It was another reason why the difference of temperature in two sides was quite low(about $5^{\circ} \mathrm{C}$ ).

To improve cooling effect, most of all, not only potential energy between two materials should be elevated, but also heat transfer should be blocked by high insulation capability. In addition, if higher conductive N-type and P-type material is developed, the cooling function by Peltier effect will also be elevated.

\section{Conclusion}

In this study, by in-situ polymerization method, the PPy coated P-type PPy-PET composite fabric was developed. After acid and $\mathrm{SOCl}_{2}$ treatment, MWNT$\mathrm{COCl}$ was transferred in surface of MWNT, and then reacted with PEI. Finally, MWNT-PEI composite materials were obtained through $\mathrm{COCl}$ ingredient of MWNT and amidation reaction. The Peltier effect of these materials was verified. Namely, the cooling effect using conductive polymer could be also verified.

Even though the difference of temperature in two materials was quite small(about $5^{\circ} \mathrm{C}$ ), due to electrical unstableness of PPy-PET conductive composite fabrics, heat transfer problem by resistance and insulation characteristics, the Peltier effect using conductive polymer was verified.

In addition, if the insulation capability of thermal emission side and absorption side is elevated, it will be able to develop optimal active cooling e-textiles for comfortable cloths.

\section{Acknowledgments}

The authors of this paper would like to thank Soongsil University for Research Fund.

\section{Reference}

1. Xiaoming Tao, "Smart fibrers, fabrics and clothing", Wood head Publishing Ltd., Cambridge, UK, pp.34-57, 2001

2. Gao Min, D.M. Rowe, Cooling performance of integrated thermoelectric microcooler, Solid-state Electronics, 43, 923-929(1999).

3. Alan J. Heeger, Semiconducting and metallic polymers : the fourth generation of polymeric materials, Synthetic Metals, 125, 23-42(2002).

4. D. Kumar, R. C. Sharma, Advances in conductive polymers, Eur. Polym. J., 34(8), 1053-1060(1998).

5. G. E. Collins, L. J. Buckley, Conductive polymercoated fabrics for chemical sensing, Synthetic Metals, 78, 98-101(1996).

6. Eva Hakansson, Akif Kaynak, Tong Lin, Saeid Nahavandi, Trevor Jones, Eric Hub, Characterization of conducting polymer coated synthetic fabrics for heat generation, Synthetic Metals, 144, 21-28(2004).

7. Akif Kaynak and Rafael Beltran, Effect of synthesis parameters on the electrical conductivity of polypyrrole-coated poly(ethylene terephthalate) fabrics, Polymer International, 52, 1021(2003).

8. Tong Lin, Lijing Wang, Xungai Wang, Akif Kaynak, Polymerising pyrrole on polyester texiles and controlling the conductivity through coating thickness, Thin Solid Films, 479, 77-82(2005).

9. Eric Hu, Akif Kaynak, Yuncang Li, Development of a cooling fabric from conducting polymer coated fibres : Proof of concep, Synthtic metals, 150, 139-143(2005).

10. Isao Yamaguchi, Takakazu Yamamoto, Soluble self-doped single-walled carbon nanotube, Materials Letters, 58, 598-603(2004).

11. J.Chen, M.A.Hamon, H.Hu, Y.Chen, A.M.Rao, P.C.Eklund, R.C.Haddon, Solution Properties of Single-Walled Carbon Nanotubes, Science, 282, 95-98(1998). 